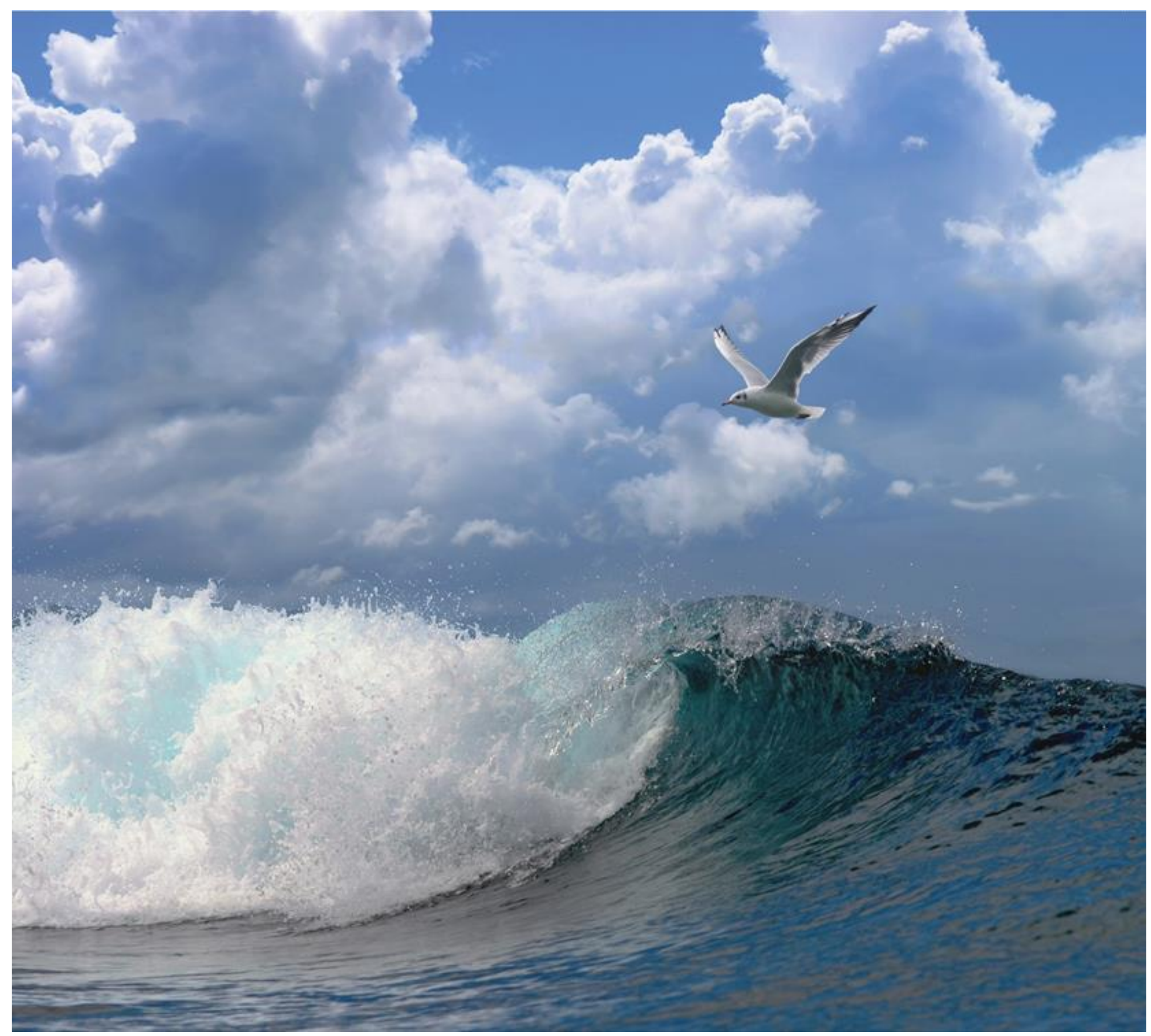

Lethal and non-lethal effects of trawling on the benthic invertebrate food web 


\section{Lethal and non-lethal effects of trawling on the benthic invertebrate food web}

Author(s): $\quad$ K.E van de Wolfshaar, T. van Kooten and A.D. Rijnsdorp

Client: $\quad$ Ministerie van Landbouw, Natuur en Voedselkwaliteit

Attn.: Mw M.H.L.Visser

Postbus 20401

2500 EK, Den Haag

Verplichtingennummer 1300021172

Publication date: March 2020

This research project was carried out by Wageningen Marine Research at the request of and with funding from the Ministry of Economic Affairs for the purposes of Policy Support Research Theme 
K.E van de Wolfshaar, T. van Kooten and A.D. Rijnsdorp, 2020. Lethal and non-lethal effects of trawling on the benthic invertebrate food web; Wageningen Marine Research report C011.20. 24 pp.

This report can be downloaded for free from: https://doi.org/10.18174/514206

Wageningen Marine Research provides no printed copies of reports

(c) Wageningen Marine Research

Wageningen Marine Research, an institute Wageningen Marine Research accepts no liability for consequential damage, nor within the legal entity Stichting for damage resulting from applications of the results of work or other data Wageningen Research (a foundation under obtained from Wageningen Marine Research. Client indemnifies Wageningen Dutch private law) represented by $\mathrm{Dr}$. Marine Research from claims of third parties in connection with this application. M.C.Th. Scholten, Managing Director All rights reserved. No part of this publication may be reproduced and / or published, photocopied or used in any other way without the written permission

KvK nr. 09098104, of the publisher or author.

WMR BTW nr. NL 8113.83.696.B16.

Code BIC/SWIFT address: RABONL2U

IBAN code: NL 73 RABO 0373599285 


\section{Contents}

$\begin{array}{llr}1 & \text { Introduction } & 5\end{array}$

2 Methods $\quad 7$

$\begin{array}{llr}2.1 & \text { Model } & 7\end{array}$

2.2 Parameters $\quad 9$

2.3 Analyses 11

$3 \quad$ Results $r$

$\begin{array}{ll}3.1 & \text { Lethal effects of trawling } \\ 3.2 & 12\end{array}$

$\begin{array}{ll}3.2 & \text { Non-lethal effects of trawling } \\ 3.3 & 13\end{array}$

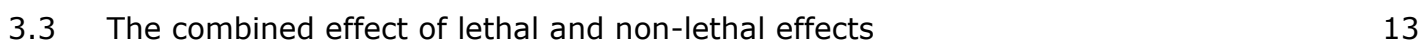

4 Discussion $r$

$5 \quad$ Quality Assurance $r$

$\begin{array}{lr}\text { References } & 19\end{array}$

$\begin{array}{lr}\text { Justification } & 23\end{array}$ 


\section{Summary}

The pulse trawl is presented as an alternative for the traditional tickler chain beam trawl. The beam trawl has a direct lethal effect on the benthic community, which is much less for the pulse trawl. However, the pulse trawl, due to its electrical field has non-lethal effects on the benthic community. The existence of such non-lethal effects have been demonstrated for different organisms and most often involve a short period of inactivity. Such a period of inactivity may have consequences at the population level as it may limit feeding. Yet the population dynamical consequences, nor food web level consequences, have been studied in experimental or field settings.

To study non-lethal and lethal effects of trawling on the benthic community a model was developed which is based on a trait-based characterization of the food web. This model describes the equilibrium dynamics of predators, filter feeders and deposit feeders. The model includes direct mortality as a function of fishing mortality and a non-lethal effect, which was incorporated as a decrease of the maximum food intake rate. This approach was based on experiments with electric pulse and benthic invertebrates. We conducted a comparative analysis of lethal and non-lethal impact of trawling on the equilibrium dynamics of the benthic food web. Only lethal effects represent a tickler chain beam trawl and a combination of lethal and non-lethal effect represents a pulse trawl. We first studied the effects of lethal and non-lethal impacts on the food web separately. We then studied the trade-off between lethal and non-lethal effects for a given total impact on the community. This approach shows how much non-lethal impact is required to compensate for a decrease in lethal effects of trawling. The study shows that lethal effects need to be replaced by non-lethal effects with similar strength in order to maintain the effect of fishing intensity on the food web. Such strong non-lethal effects are unlikely to occur in the field based on experiments assessing the impact of electricity on benthic macro-invertebrates and trawling intensity. In other words, the combined non-lethal and lethal effects of the pulse trawl are unlikely to have a similar effect on the macro-invertebrate benthic community compared to the lethal effects of the traditional trawl. 


\section{Introduction}

The effect of trawl fishing gear on the seafloor has been established and described in terms of mechanical disturbance, such as penetration depth (e.g. Depestele et al. (2019)) and sediment resuspension (O'Neill \& Summerbell, 2011), as well as in terms of mortality of benthic organisms on and in the seafloor (e.g. (Sciberras et al., 2018)).

As an alternative to the traditional trawls which use tickler chains to activate fish, pulse trawls were developed to reduce ecological impacts, improve selectivity and reduce fuel cost (Haasnoot, Kraan, \& Bush, 2016). These pulse trawls use an electric stimulus to immobilise the fish (de Haan, Fosseidengen, Fjelldal, Burggraaf, \& Rijnsdorp, 2016; Soetaert, Decostere, Polet, Verschueren, \& Chiers, 2015). Pulse trawls have a higher catch efficiency for sole, but a lower catch efficiency for other fish species and benthic organisms (Poos et al. in prep; ICES, 2018; van Marlen, Wiegerinck, van Os-Koomen, \& van Barneveld, 2014). Pulse trawls do not use tickler chains and have therefore a less deep penetration in the sea bed and are less damaging to benthic fauna on passage (Depestele et al., 2019; Soetaert, Decostere, et al., 2015). Tiano et al. (2019) compared the effect of bottom trawl disturbance by a pulse trawl and a tickler chain beam trawl on the benthic community metabolism and showed that tickler chain trawling exhibits more prominent alterations than pulse trawling (of type PulseWing) on benthic biogeochemical processes.

The invertebrates in the benthic food web are effected differently by different trawling gears because of differences in species characteristics such as mobility, burial depth or longevity, but also due to differences in gear characteristics such as penetration depth, gear width or vessel speed (Eigaard et al., 2016; Hiddink et al., 2019; Sciberras et al., 2018). The bycatch and direct lethal effects of benthic invertebrates is less for the pulse trawl than for the traditional beam trawl (van Marlen et al., 2014). There have been some experimental studies on the effects of the electricity used with pulse trawling on benthic invertebrates.

Smaal and Brummelhuis (2005) and van Marlen et al. (2009) exposed over 20 different species, including echinoderms, polychaetes, bivalves, crustaceans and decapods, to worst-case pulse conditions showing no consistent negative effects. In one crab species, results suggested a reduction in food intake. A more elaborate study with shrimp and ragworm did not reveal any mortality or injuries (Soetaert, Chiers, et al., 2015). Only when shrimps were exposed 20 times in 4 days, an exposure frequency that does not occur in the sea, a reduced survival rate was observed (0.6) (Soetaert et al., 2016). Boute et al (in prep) studied the response of a selection of benthic organisms to pulse exposure. Preliminary results suggest that electrical pulses may increase burrowing behaviour as animals try to escape the disturbance. These results suggest that exposure to electrical pulses will affect the normal behaviour of animals which may reduce their food intake or increase their activity level but will unlikely add to the direct mortality imposed by the mechanical disturbance of the pulse trawl.

All these examples above report on the individual level effects of electricity and findings on the number of individuals in the catch. However, the effects of electricity on the food web have hitherto not been addressed. This would of course be difficult in a field setting, although mesocosm experiments may provide opportunities for such studies. Nonetheless, impacts of non-lethal effects at food web level remain under addressed. To that end, a modelling approach was used which translates effects at individual level to into a food web context.

Here we study the potential of non-lethal effects of fishing on the benthic food web in relation to lethal effects, in particular how much non-lethal impact is required to compensate food web response for a decrease in lethal effects of fishing. Thus, we studied how strong the non-lethal effect must be so that the pulse trawl has the same effect as the traditional trawl on the food web. Thereafter, we estimated the expected non-lethal effect of the pulse trawl on an individual, based on reported responses of benthic organisms to electric fields and trawl frequencies. Although these two measures (from model and field) cannot be directly linked, their relative strength does inform about the expected impact of the pulse trawl on the food web in a field setting.

For this purpose a model describing the dynamics of a simplified benthic invertebrate food web is used. The food web model used describes the benthic food web based on three species groups (van de Wolfshaar et al. submitted). These groups were defined based on a trait analysis (Bolam, Coggan, Eggieton, Diesing, \& Stephens, 2014; Bremner, Rogers, \& Frid, 2006; van Denderen et al., 2015) and consist of predators/scavengers, filter/suspension feeders and deposit feeders. These three groups are general guilds that are present in the most, if not all, benthic ecosystems (Bolam et al., 2014). The 
group of predators consist of larger free-living species in fila such as annelids, cnidaria and crustaceans. The group of filter/suspension feeders is comprised of mostly sessile tube-dwelling species in fila such as molluscs, bryozoa and cnidaria. The group of deposit feeders consists of mostly burrowing species in fila such as annelids, crustaceans and molluscs and are mostly free living or tube-dwelling. The non-lethal effects were incorporated as a down-scaling of the intake rate of benthic invertebrates as suggested from experiments (van Marlen et al., 2009), (Tiano unpublished results). 


\section{Methods}

\section{$2.1 \quad$ Model}

We use the stage-structured biomass model framework (De Roos et al., 2008) to model the benthic food web. The model consists of 3 benthos groups: filter feeders $(F)$, deposit feeders $(D)$ and predators $(P)$. Each of these functional groups is modelled as 2 separate life stages (juveniles $j$ and adults $a$ ), because these engage in different ecological interactions (Figure 1). This model has been used to study the food web interactions in relation to trawling (van de Wolfshaar et al. submitted).

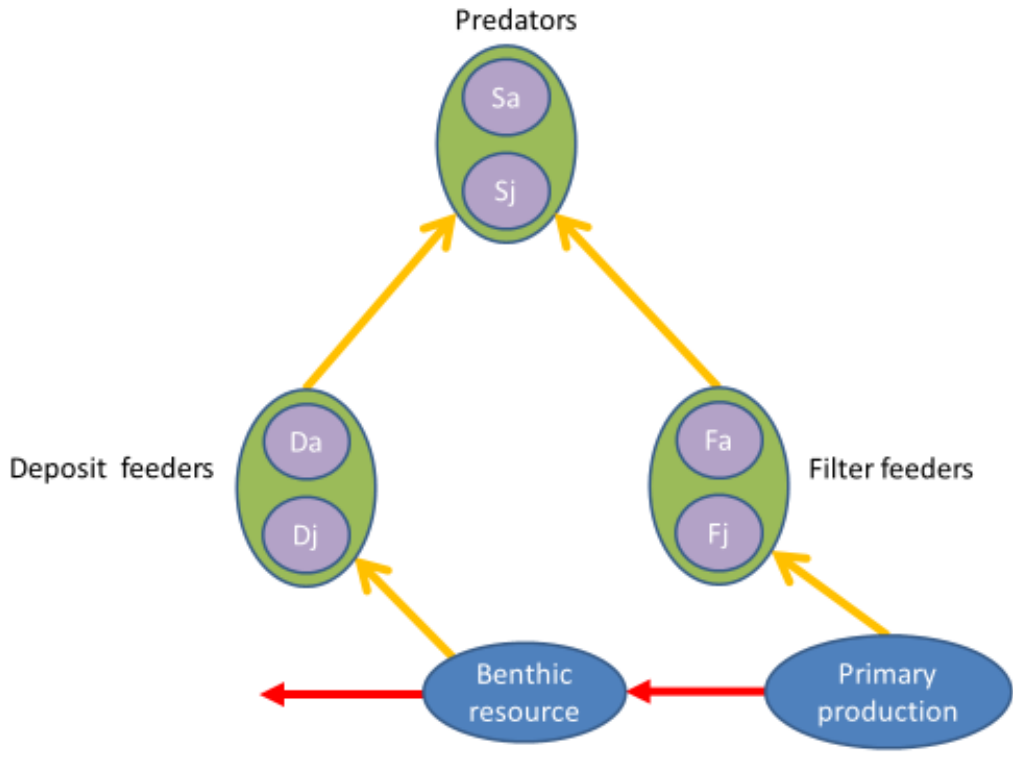

Figure 1. Food web composition with predators, deposit feeders and filter feeders.

The model contains phytoplankton $(R)$, used by the filter feeders. This phytoplankton follows semichemostat dynamics and has a loss term based on deposition on the seabed where it adds to the benthic resource (B) (Figure 1). Phytoplankton dynamics is hence described by

$$
\frac{d R}{d t}=r\left(R_{m}-R\right)-p R-C_{R}
$$

Where $r$ is the resource renewal rate and $R_{m}$ is the maximum resource abundance in absence of consumption and precipitation. We use semi-chemostat resource dynamics rather than the more common logistic growth, because we consider that only the near-bottom fraction of the water mass is available for phytoplankton consumption by filter feeders, whereas the bulk of primary production production occurs in the upper water layers and reaches the $\mathrm{R}$ compartment by water mixing and particles sinking. Hence, phytoplankton production is positive even when $R=0$. Phytoplankton is deposited to the seabed at constant rate $p$, and consumed by filter feeders given by $C_{R}$. Benthic resource $B$ increases by deposition of phytoplankton $R$ and decreases by deposit feeder consumption $\left(C_{B}\right)$ and loss to biologically inactive deep sediments (at rate $q$ ):

$$
\frac{d B}{d t}=p R-q B-C_{B}
$$

The key aspects of the structured biomass community framework are the equations for biomass accumulation governing growth and reproduction, and the equation for maturation. The biomass accumulation is based on the net result from feeding intake and maintenance costs.

$$
v_{i}=\sigma I_{i}-T_{i}
$$


(where $i \in\left\{D_{j}, D_{a}, F_{j}, F_{a}, P_{j}, P_{a}\right\}$ ). Here $I_{i}$ is the mass-specific intake rate and $T_{i}$ is the mass-specific maintenance rate, and $\sigma$ is the conversion efficiency of resource to consumer biomass. Transfer from juvenile to adult biomass through maturation $(\gamma)$ is governed by

$$
\gamma_{k}=\frac{v_{k_{j}}-\mu_{k_{j}}}{\left(1-z_{k}^{1-\frac{\mu_{k_{j}}}{v_{k_{j}}}}\right)}
$$

(where $k \in\{D, F, P\}$ ). This function is derived in such a way that it corresponds exactly to a model with continuous size structure under equilibrium dynamics, and approximates it otherwise (De Roos et al., 2008). Maturation is a function of $v$, the net biomass production rate, the mortality rate $\mu$, and $z$, which is the ratio between the size at birth and the size at maturation.

The equations for $v_{i}$ and $\gamma_{k}$ noted above are the basis of the dynamics of filter feeders $\left(F_{j}\right.$ and $\left.F_{a}\right)$, deposit feeders $\left(D_{j}\right.$ and $\left.D_{a}\right)$ and predators $\left(P_{j}\right.$ and $\left.P_{a}\right)$, where the index indicates the juvenile $(j)$ or adult (a) stage:

$$
\begin{aligned}
\frac{d D_{j}}{d t} & =v_{D_{a}}^{+}\left(I_{D_{a}}\right) D_{a}+v_{D_{j}}\left(I_{D_{j}}\right) D_{j}-\gamma_{D_{j}}^{+}\left(I_{D_{j}}\right) D_{j}-\mu_{D_{j}} D_{j} \\
\frac{d D_{a}}{d t} & =\gamma_{D_{j}}^{+}\left(I_{D_{j}}\right) D_{j}+v_{D_{a}}\left(I_{D_{a}}\right) D_{a}-v_{D_{a}}^{+}\left(I_{D_{a}}\right) D_{a}-\mu_{D_{a}} D_{a} \\
\frac{d F_{j}}{d t} & =v_{F_{a}}^{+}\left(I_{F_{a}}\right) F_{a}+v_{F_{j}}\left(I_{F_{j}}\right) F_{j}-\gamma_{F_{j}}^{+}\left(I_{F_{j}}\right) F_{j}-\mu_{F_{j}} F_{j} \\
\frac{d F_{a}}{d t} & =\gamma_{F_{j}}^{+}\left(I_{F_{j}}\right) F_{j}+v_{F_{a}}\left(I_{F_{a}}\right) F_{a}-v_{F_{a}}^{+}\left(I_{F_{a}}\right) F_{a}-\mu_{F_{a}} F_{a} \\
\frac{d P_{j}}{d t} & =v_{P_{a}}^{+}\left(I_{P_{a}}\right) P_{a}+v_{P_{j}}\left(I_{P_{j}}\right) P_{j}-\gamma_{P_{j}}^{+}\left(I_{P_{j}}\right) P_{j}-\mu_{P_{j}} P_{j} \\
\frac{d P_{a}}{d t} & =\gamma_{P_{j}}^{+}\left(I_{P_{j}}\right) P_{j}+v_{P_{a}}\left(I_{P_{a}}\right) P_{a}-v_{P_{a}}^{+}\left(I_{P_{a}}\right) P_{a}-\mu_{P_{a}} P_{a}
\end{aligned}
$$

In these equations, terms superscripted ' + ' indicate the value lies within the interval $[0, \infty]$, e.g. $v_{\mathrm{P}_{\mathrm{a}}}^{+}=$ $\max \left(0, v_{\mathrm{P}_{\mathrm{a}}}\right)$. This is necessary to ensure that biomass flow from juveniles to adults by maturation and from adults to juveniles by reproduction does not reverse under adverse food conditions. Rather than resorb juveniles by unrealistic 'inverted reproduction', the adult stages lose biomass under starvation. Finally, dynamics are determined by the mortality rates $\mu$. Under sufficient food, adults are assumed to convert all biomass gains into offspring, and do not grow.

The feeding relationships between the groups in the model are summarized in Fout!

Verwijzingsbron niet gevonden.Fout! Verwijzingsbron niet gevonden.. All consumption follows a Holling type II functional response, with full complementarity of resources (sensu Tilman and Sterner (1984)). Intake rates for each consumer group in the model are limited by their biomass specific maximum intake rate $M$ and half-saturation constant $H$. Deposit feeders and filter feeders feed only on a single resource compartment, and hence their intake is given by

$$
I_{D_{j}}=M_{D_{j}} \frac{B}{H+B}, \quad I_{D_{a}}=M_{D_{a}} \frac{B}{H+B}, \quad I_{F_{j}}=M_{F_{j}} \frac{R}{H+R} \text { and } I_{F_{a}}=M_{F_{a}} \frac{R}{H+R}
$$

Consequently, the grazing of resources $R$ and $B$ is given by

$$
C_{R}=I_{F_{j}} F_{j}+I_{F_{a}} F_{a} \text { and } C_{B}=I_{D_{j}} D_{j}+I_{D_{a}} D_{a}
$$

respectively. Predators feed on juvenile filter feeders and juvenile deposit feeders, and hence their intake is given by

$$
I_{P j}=M_{P_{j}} \frac{F_{j}+D_{j}}{H+F_{j}+D_{j}} \text { and } I_{P a}=M_{P_{a}} \frac{F_{j}+D_{j}}{H+F_{j}+D_{j}}
$$

for juveniles and adults respectively. To model the non-lethal effects of gear damage the intake rates of all benthic groups are scaled with fishing intensity $E$, using coefficient $\beta$ for all groups. The scaling is linear, following the function

$$
I_{u}^{*}=(1-\beta E) * I_{u}
$$

(where $u \in\left\{D_{j}, D_{a}, F_{j}, F_{a}, P_{j}, P_{a}\right\}$ ). In this way the intake rate is maximized for $\beta=0$, and zero for $\beta=1$. 
Mortality of filter feeders, deposit feeders and predators consists of a constant stage-specific background mortality and mortality from trawling. Furthermore, juvenile filter feeders and deposit feeders also suffer mortality from predation by invertebrate predators.

We can now derive total benthic mortality, which for the juvenile filter feeders and deposit feeders equals

and

$$
\mu_{D_{j}}=\mu_{b_{D_{j}}}+\rho E Q_{D_{j}}+M_{P_{j}} \frac{P_{j}}{H+F_{j}+D_{j}}+M_{P_{a}} \frac{P_{a}}{H+F_{j}+D_{j}}
$$

$$
\mu_{F_{j}}=\mu_{b_{F_{j}}}+\rho E Q_{F_{j}}+M_{P_{j}} \frac{P_{j}}{H+F_{j}+D_{j}}+M_{P_{a}} \frac{P_{a}}{H+F_{j}+D_{j}}
$$

where $\mu_{b}$ is a stage-specific constant background mortality rate, $\rho$ is the scalar of lethal gear damage, $Q_{x}$ is the stage-specific relative vulnerability of each benthic group/stage $x$, to trawling, of which $E$ denotes the intensity. The next two terms are the predation mortality imposed by juvenile and adult predators.

For the remaining benthic groups, mortality equals:

$$
\mu_{u}=\mu_{b_{u}}+\rho E Q_{u}
$$

(where $u \in\left\{D_{a}, F_{a}, P_{j}, P_{a}\right\}$ ).

\subsection{Parameters}

Parameter values are presented in Table 1. Because we model biomass in each model compartment, rather than number of individuals, all rate parameters (those with units $t^{-1}$ ) are mass-specific. The functional groups in our model should be interpreted as 'typical members' of the group they represent. This has important consequences for the parameterization. Rather than referring to species-specific values, we use averages for a large number of species, and allometric scaling laws to derive representative parameter values.

Per unit biomass values for maximum intake $M$ and maintenance rate $T$ are assumed inversely proportional to the quarter power of adult body mass (for which we use body mass at maturation), and we assume further that mass-specific maintenance is generally in the order of $10 \%$ of the massspecific maximum intake rate (De Roos et al., 2007; Gillooly, Brown, West, Savage, \& Charnov, 2001; Peters \& Wassenberg, 1983). Hence, we assume that

$M=W_{\text {mat }}^{-0.25}$ and $T=0.1 W_{\text {mat }}^{-0.25}$

We used an extensive data set of benthic invertebrate samples from the Dutch Continental Shelf area in the North Sea (van Denderen, Hintzen, Rijnsdorp, Ruardij, \& van Kooten, 2014) to derive the average weight (W) of individuals in each benthic functional group ( $F, D$ and $P$ ). Using a biological trait database (Bolam et al., 2014), we used trait information on feeding mode and maximum size to estimate the average size for each of the benthos functional groups in the model. Similarly, we used trait information on longevity to calculate group-specific values for the background mortality $\left(\mu_{b}\right)$. These data were collected using a Reineck box-corer (Daan \& Mulder, 2009). However, this device is not particularly suitable for sampling the generally larger, mobile (epi-) benthic predators. For these, data from the ICES Beam Trawl Survey (using an $8 \mathrm{~m}$ beam trawl with a $40 \mathrm{~mm}$ cod end mesh size in the North Sea) were used.

The maximum resource density $R m$ and half-saturation density $\mathrm{H}$ are expressed as biomass per unit volume and therefore the only parameters containing the unit volume. $\mathrm{H}$ can be set to 1 without loss of generality, as this merely implies a scaling of the units of the total system volume (Van Leeuwen, De Roos, \& Persson, 2008). Maximum resource density $R m$ is then expressed as multiples of the halfsaturation density. It was set to an arbitrary value such that all three benthic groups persist in the system (Van de Wolfshaar et al. submitted). A conversion efficiency $(\sigma)$ of 0.5 is used for conversion of both resource and consumer biomass (Peters \& Wassenberg, 1983). The deposition rate of the phytoplankton resource was set to 0.2 , in accordance with field estimates (pers. com. Karline Soetaert). The decay rate of the benthic resource was estimated to be half of the deposition rate (pers. com. Karline Soetaert). 
The proportionality constants $(\mathrm{Q} \mathrm{i})$ for the direct mortality per unit trawling intensity $\mathrm{E}$ (for beam trawls) were taken from a recent meta-analysis (Sciberras et al., 2018). The constants were scaled by setting the highest value (the effect on predators) to 1 (Table 1). This approach means that trawling intensity $\mathrm{E}$ should be interpreted as a relative measure only. The lethal mortality is scaled with $\rho$. We assume that the pulse trawl imposes half of the lethal effects of the traditional beam trawl ( $\rho=$ 0.5)(Rijnsdorp, de Haan, Smith, \& Strietman, 2016).

Table 1: Parameters and their values used in the model

\begin{tabular}{|c|c|c|c|}
\hline Parameter & Default value & Units & Explanation \\
\hline$E$ & varied & $d^{-1}$ & Trawling intensity \\
\hline$R_{m}$ & 6 & $g / l$ & Scaled maximum phytoplankton biomass density \\
\hline$r$ & 0.1 & $d^{-1}$ & Phytoplankton turnover rate \\
\hline$W_{d}$ & 4 & $\mathrm{~g}$ & Individual body-mass of adult deposit feeders \\
\hline$W_{f}$ & 9 & $\mathrm{~g}$ & Individual body-mass of adult filter feeders \\
\hline$W_{p}$ & 11 & $\mathrm{~g}$ & Individual body-mass of adult predators \\
\hline$T_{P}, T_{F}, T_{D}$ & $\begin{array}{l}0.055,0.058, \\
0.071\end{array}$ & $d^{-1}$ & $\begin{array}{l}\text { Mass-specific maintenance rate of predators, filter } \\
\text { feeders and deposit feeders }\end{array}$ \\
\hline$M_{P}, M_{F}, M_{D}$ & $\begin{array}{l}0.55,0.58, \\
0.71\end{array}$ & $d^{-1}$ & $\begin{array}{l}\text { Mass-specific intake rate of predators, filter feeders and } \\
\text { deposit feeders }\end{array}$ \\
\hline$H$ & 1 & $g / l$ & Half saturation constant \\
\hline$\sigma$ & 0.5 & - & Conversion efficiency \\
\hline$p$ & 0.2 & $d^{-1}$ & Deposition rate of $\mathrm{R}$ to $\mathrm{B}$ \\
\hline$q$ & 0.1 & $d^{-1}$ & Loss rate from $B$ \\
\hline$\rho$ & 1 & - & Coefficient of lethal trawling effect on benthos \\
\hline$\beta$ & 0 & - & Coefficient of non-lethal trawling effect on benthos \\
\hline$\mu_{b_{D_{j}}}, \mu_{b_{D_{a}}}$ & 0.009 & $d^{-1}$ & Background mortality deposit feeders \\
\hline$\mu_{b_{F_{j}}}, \mu_{b_{F_{a}}}$ & 0.005 & $d^{-1}$ & Background mortality filter feeders \\
\hline$\mu_{b_{P_{j}}}, \mu_{b_{P_{a}}}$ & 0.012 & $d^{-1}$ & Background mortality predators \\
\hline$z$ & 0.01 & - & Ratio of mass at birth to mass at maturation \\
\hline$Q_{p}$ & 1 & - & Trawling mortality scaling coefficient for predators \\
\hline$Q_{d}$ & 0.58 & - & Trawling mortality scaling coefficient for deposit feeders \\
\hline$Q_{f}$ & 0.95 & - & Trawling mortality scaling coefficient for filter feeders \\
\hline
\end{tabular}




\subsection{Analyses}

The model builds upon the model described in Van de Wolfshaar et al. (submitted), and adds nonlethal effects of trawling on intake rates.

We conduct a comparative analysis of lethal and non-lethal impact of trawling on the equilibrium dynamics of the benthic food web. We first studied the effects of lethal and non-lethal impacts on the food web separately as function of trawling intensity. We then studied the trade-off between lethal and non-lethal effects for a given total impact on the community. In order to study such combined effect of a decrease in lethal effects and an increase in non-lethal effects, as is suggested to occur when switching from a traditional beam trawls with tickler chains to a pulse trawl using electricity, we set the fishing intensity (E) to a fixed value. We then determine the total benthic biomass, all groups and stages combined, in equilibrium. Next step is a reduction of the lethal effect of trawling (decrease of $\rho)$, and we study the strength of the non-lethal effect $(\beta)$ needed to keep the total biomass in the system constant. We conduct this analysis for five different fixed values for fishing intensity. This approach shows how much non-lethal impact is required to compensate for a decrease in lethal effects of fishing.

All analyses were conducted using Content (Kuznetsov, Levitin, \& Skovoroda, 1996), a software package for numerical analysis of dynamical systems. 


\section{Results}

\subsection{Lethal effects of trawling}

We calculated the equilibrium biomass of the three benthic groups (predators, deposit feeders and filter feeders) with increasing trawling intensity. Here, we model trawling intensity as lethal effects only, mimicking a traditional beam trawl $(\beta=0$ and $\rho=1)$ (Figure 2 . The biomass of the benthic groups $(P, D$ and $F)$ as a function of the trawling intensity (E) (left panel) and the change in resource density of phytoplankton $(R)$ and the benthic resource $(B)$ (right panel). In this figure there are only lethal effects and no non-lethal effects, mimicking a traditional beam trawl $(\beta=0$ and $\rho=1)$. Black lines represent the adult stages and grey lines represent the juvenile stages., left panel). These lethal effects of trawling are modelled as a mortality term for all groups. At low trawling intensity there is a high equilibrium biomass of juvenile predators and deposit feeders, while filter feeders have low biomass. Trawling intensity affects the predators most, and higher trawling intensity leads to lower equilibrium predator biomass and ultimately a loss in predators in the food web. Fewer predators means less predation. This reduction is so strong that it outweighs the direct increase in mortality for filter feeders. The result is an emergent positive relationship between trawling intensity on filter feeder equilibrium biomass: more trawling is associated with a higher filter feeder biomass. In turn, this increase of filter feeders reduces the phytoplankton resource and the deposition to the benthic resource (Figure 2 . The biomass of the benthic groups ( $P, D$ and $F$ ) as a function of the trawling intensity (E) (left panel) and the change in resource density of phytoplankton (R) and the benthic resource (B) (right panel). In this figure there are only lethal effects and no non-lethal effects, mimicking a traditional beam trawl $(\beta=0$ and $\rho=1)$. Black lines represent the adult stages and grey lines represent the juvenile stages., right panel) and hence lower food availability for deposit feeders at higher trawling intensity. This negative effect on deposit feeders aligns with the direct mortality effect. The result is a negative relationship between trawling intensity and equilibrium deposit feeder biomass. Overall, there is an increase in total benthic biomass, driven by the higher filter feeder equilibrium biomass. Eventually, trawling intensity becomes so high that none of the benthos groups can persist.
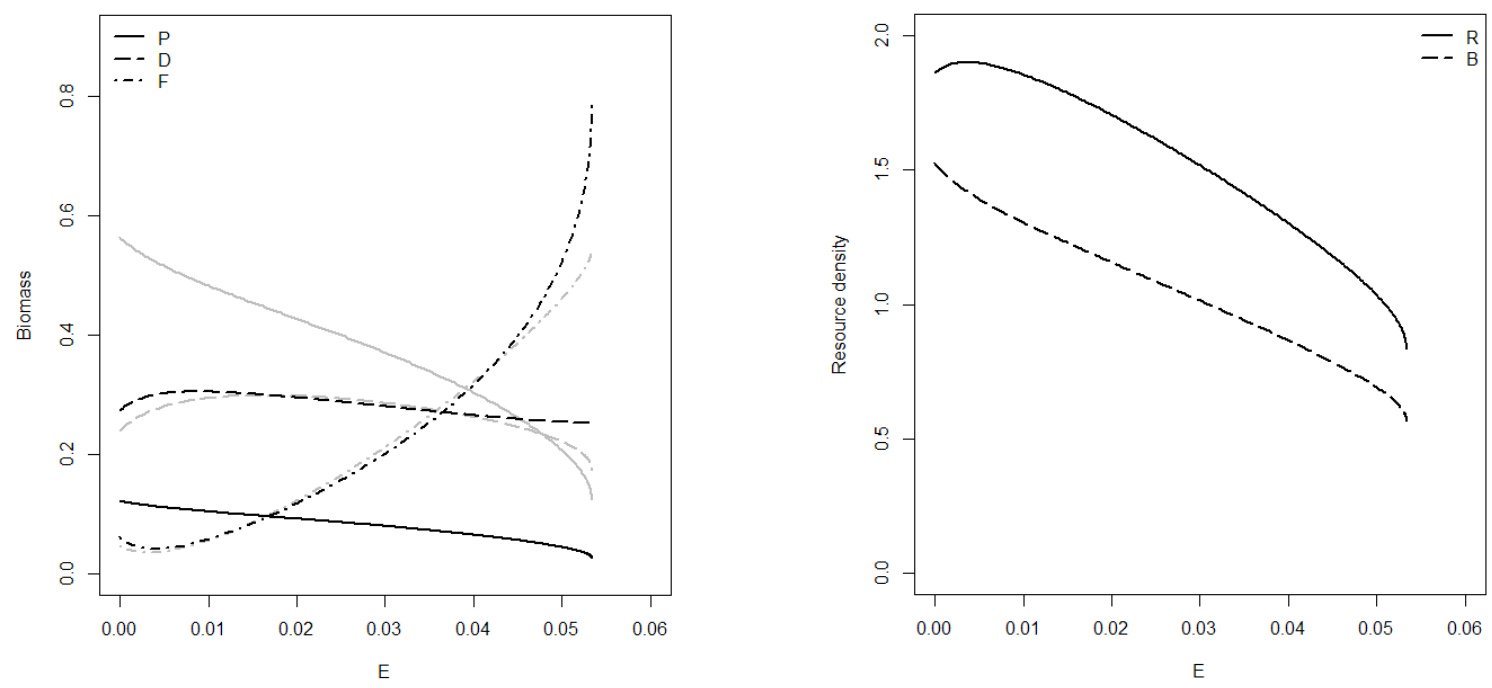

Figure 2. The biomass of the benthic groups ( $P, D$ and $F)$ as a function of the trawling intensity (E) (left panel) and the change in resource density of phytoplankton $(R)$ and the benthic resource $(B)$ (right panel). In this figure there are only lethal effects and no non-lethal effects, mimicking a traditional beam trawl $(\beta=0$ and $\rho=1)$. Black lines represent the adult stages and grey lines represent the juvenile stages. 


\subsection{Non-lethal effects of trawling}

Non-lethal effects of trawling are implemented as a reduction of the intake rate of all three benthos groups. The patterns of changing equilibrium biomass with increasing trawling effort are similar to those observed with lethal effects (Figure 3). The range of trawling intensity along which the pattern occurs is wider, but this is a result of parameter scaling choices, rather than a model result. The trawling-induced reduction in intake rate, although equal for all groups, leads to a decreased predator biomass and hence a reduction in predation pressure on filter feeders and deposit feeders. In the filter feeders, this outweighs the trawling-induced reduction in intake rate, leading to higher equilibrium biomass of filter feeders at higher trawling intensity. The biomass of deposit feeders increases with increasing fishing intensity, which differs from the response found using lethal effects. This is caused by the reduced intake rate of the filter feeders which, despite high biomass. This directly limits the degree to which the filter feeders can reduce their planktonic resource, and hence the rate at which it deposits. The result is that enough of the primary production deposits to facilitate a positive net effect of trawling intensity on deposit feeder equilibrium biomass. This is illustrated in Figure 3 (right panel) showing a decrease in phytoplankton but a less steep decrease in benthic resource density. Eventually, trawling intensity becomes so high that none of the benthos groups can persist.
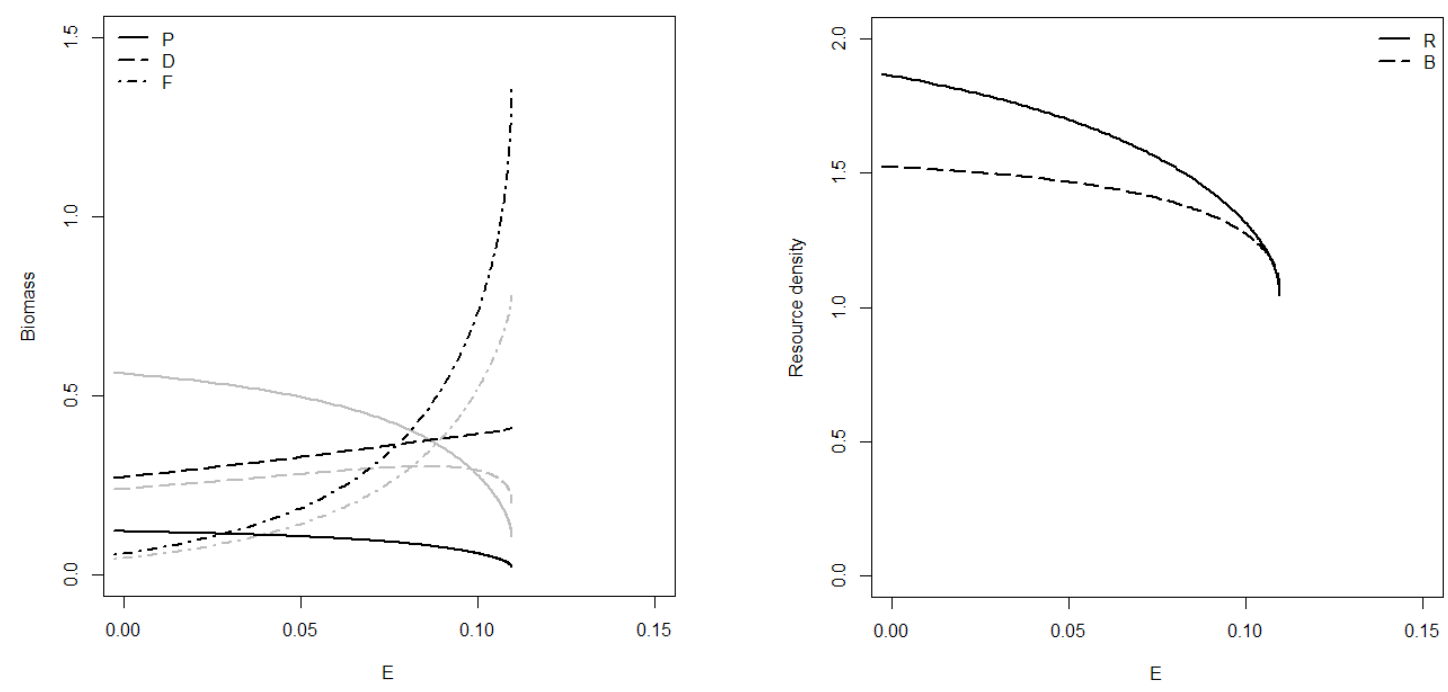

Figure 3. The biomass of the benthic groups (left panel) and resource density (right panel) as a function of the trawling intensity $(E)$ with only non-lethal effects $(\beta=5$ and $\rho=0)$. Black lines represent the adult stages and grey lines represent the juvenile stages.

\subsection{The combined effect of lethal and non-lethal effects}

The interplay of lethal and non-lethal effects was studied by reducing the lethal effect (decrease of $\rho$ ) and simultaneously increasing the non-lethal effect (increase of $\beta$ ) using 5 different values of trawling intensity. This was done while keeping total food web biomass constant for each value of trawling intensity (see section 2.3). The biomass isoclines are plotted as function of the fraction of lethal effects $(\rho)$ and the fraction of the intake rate remaining when non-lethal effects occur (Figure 4). When the strength of the lethal effects is reduced, a reduced intake rate is necessary to keep total equilibrium biomass constant (Figure 4). At high levels of lethal effects, e.g. between 0.6 and 1 , the decrease in intake rate to compensate needs to be the same order of magnitude as the decrease in lethal effects to maintain the same overall effect on biomass. This means that the indirect effects need to be as strong as the direct, lethal, effects for a similar community response to trawling. The rate at which the intake rate needs to be scaled down (the steepness of the curves) is higher at higher trawling intensity. However, when the lethal effects approach very low values, less compensation in the intake rate is needed to maintain the biomass. The direction of the curves reverses at very strongly reduced lethal effects, combined with low trawling intensity. This is caused by food web interactions. 


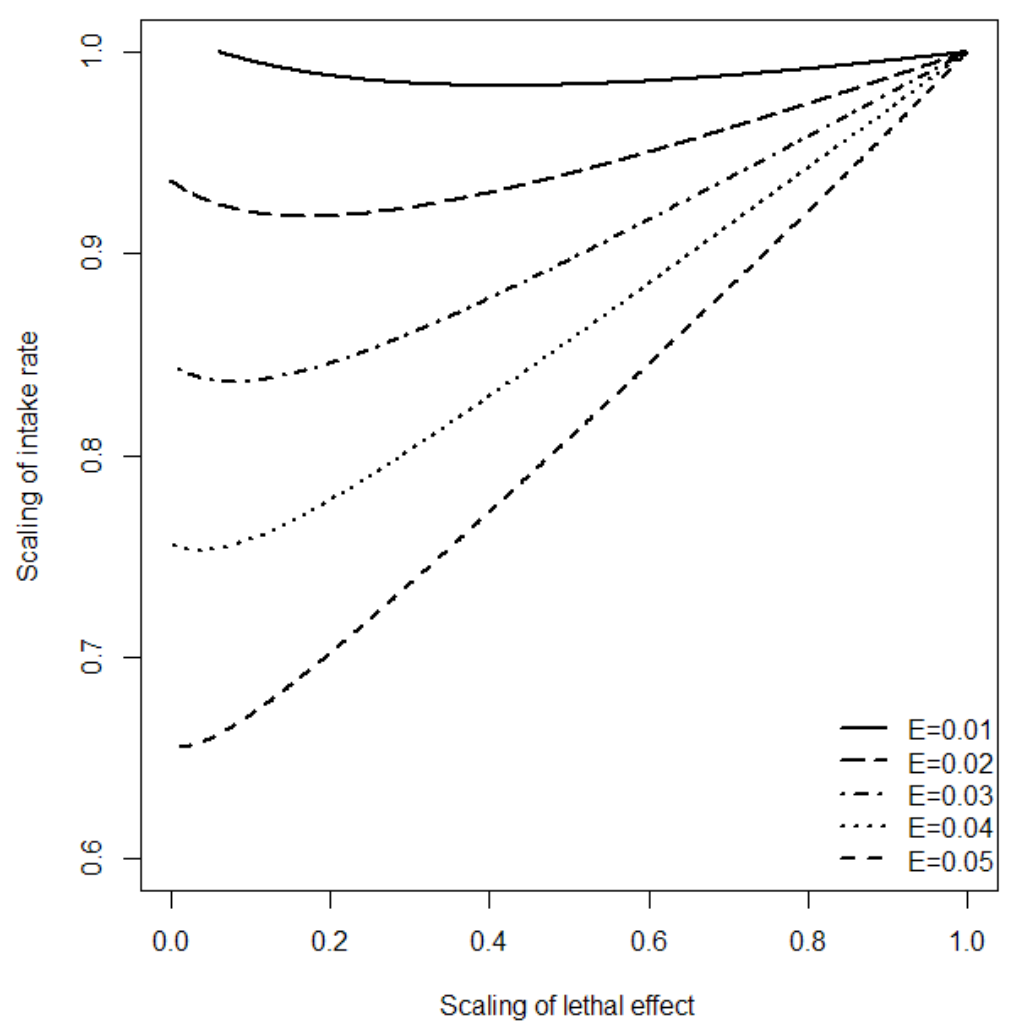

Figure 4. Biomass isoclines for different values of trawling intensity $(E)$, as a function of the reduction of lethal effects $(x$-axis, $\rho$ ) and the fraction of the intake rate $(1-\beta \cdot E)$.

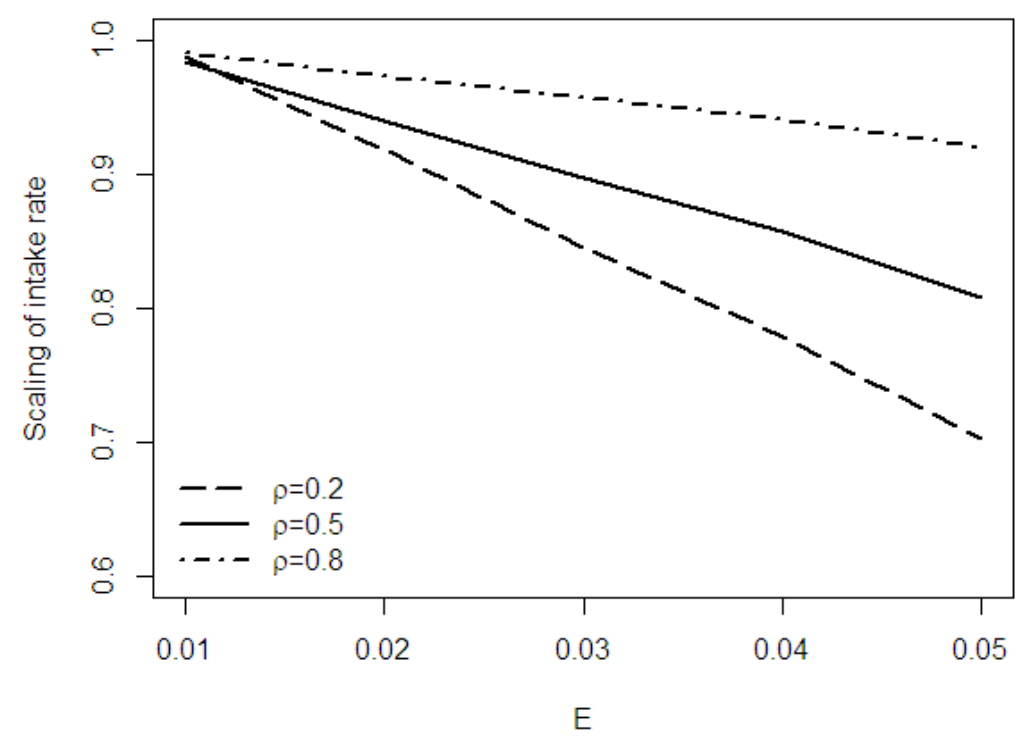

Figure 5. Plotted is the non-lethal effect needed to maintain biomass at trawling intensity $E$, for different fractions of lethal effect (i.e. vertical cross sections from Figure 4). The solid line represents a 0.5 reduction of lethal effect, which is suggested to represent the lethal effect fraction of the pulse trawl compared to the traditional trawl. 
The relationship between trawling intensity and the non-lethal effects as plotted in Figure 4 can be displayed in a different manner (Figure 5). For a given reduction in lethal effect $(\rho)$ the relationship between the scaling of the intake rate and the trawling intensity can be plotted. This shows that an increasing trawling intensity leads to a decrease in intake rate in order to maintain a constant total community biomass. If the lethal effects are strongly reduced (e.g. $\rho=0.2$ ) a stronger reduction of the intake rate is needed compared to a mild reduction in lethal effects (e.g. $\rho=0.8)$ to maintain a constant biomass. Assuming that the pulse trawl exerts half of the lethal mortality compared to the traditional trawl ( $\rho=0.5$, solid line in figure $4 B$ ), the intake rate needs to be reduced to 0.8 of its original value (at $E=0.05$ ) for the pulse trawl to have the same effect on community biomass as the traditional trawl.
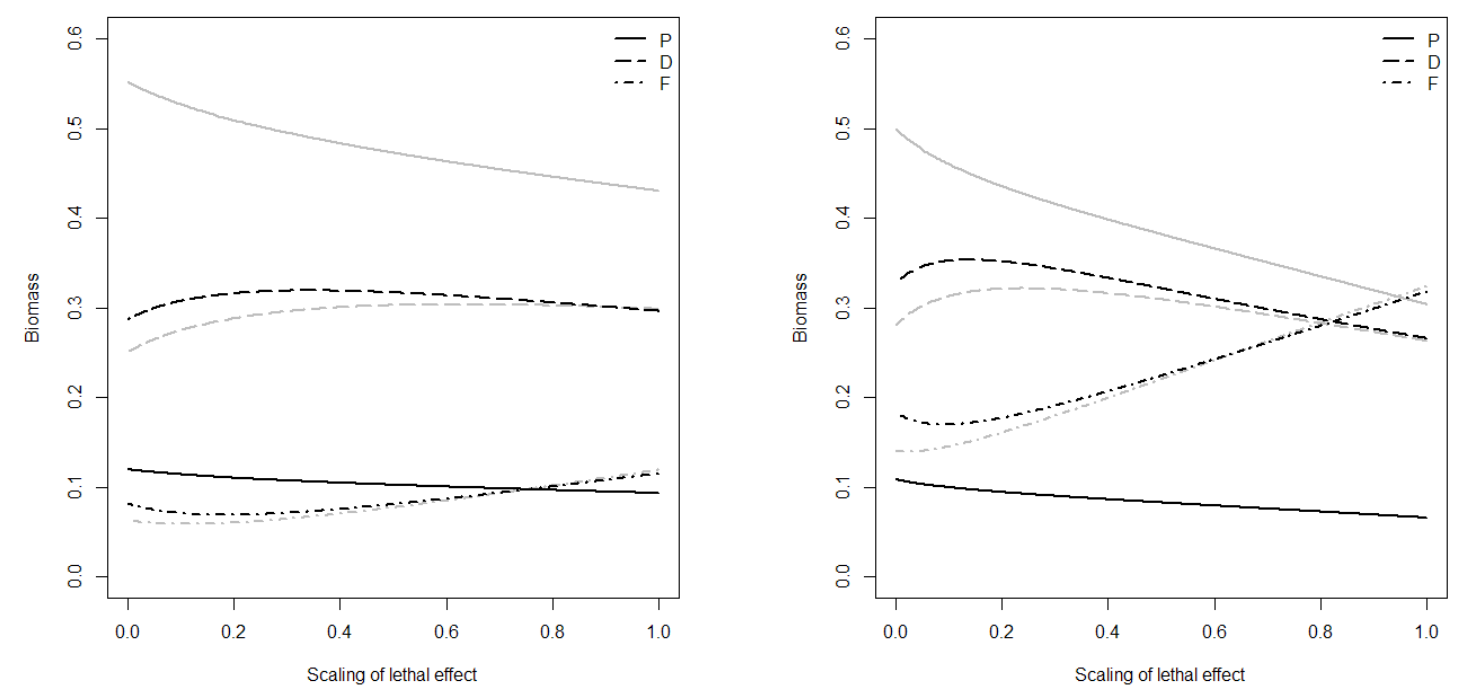

Figure 6. A breakdown of the (constant) total food web biomass into biomass of juveniles (grey) and adults (black) of the three groups plotted as function of lethal effects ( $x$-axis, $\rho$ ) and reduction of the intake rate (Figure 4 ). Note that the total biomass remains the same. Left panel: $E=0.02$. right panel: $E=0.04$.

While the total community biomass is kept constant, its distribution over the different groups changes (Figure ). Replacing lethal by non-lethal effects (moving leftwards along the $x$-axis in figure 6) leads to a higher predator equilibrium biomass. Filter feeder equilibrium biomass shows the opposite pattern, because the increase in (juvenile) predator biomass means a higher predation pressure. This results in their decreased equilibrium biomass. In turn, the reduction in filter feeders leads to higher inflow of food for the deposit feeders. The net effect is that adult deposit feeder biomass increases due to this increase in resources. Juvenile deposit feeders are sensitive to predation mortality and therefor their biomass increases less with the increase in resources than that of the adults. This occurs despite a decrease in intake rate of the deposit feeders. At a strong reduction of the lethal effects the intake rate of all groups is less hampered. Because the predators have again a higher intake rate, predation mortality on the juvenile filter and deposit feeders increases. Yet, the intake rate of the filter feeders increases as well, resulting in a net increase in filter feeder biomass. The deposit feeders not only suffer from increased predation mortality, they also face a reduction in resources now that the filter feeders increase in biomass and reduce phytoplankton levels. The increase in intake rate of the deposit feeders cannot counter these food web effects, resulting in a decrease in deposit feeders biomass at low values of lethal gear effects.

When the trawling intensity is higher, the shift in biomass distribution over the benthic groups with changing lethal effects is more pronounced (Figure, right panel). This is because the non-lethal effects have to make up more trawling related mortality to keep the biomass constant, yielding a stronger response in food web interactions. 
A reduction of lethal effects, either by reduced harvesting intensity or by downscaling the lethal effects of the gear will reduce mortality and promote predation pressure on filter and deposit feeders. So, in order for a trawl with less lethal effects to have the same effect on total food web biomass, non-lethal effects need to compensate the biomass losses through mortality with a reduction in biomass production. Different, and especially non-linear, feedback loops drive the dynamics of the food web, based on lethal or non-lethal interactions. 


\section{Discussion}

The consequences of pulse trawl compared to a traditional beam trawl on a benthic community were studied using a mathematical model of the benthic food web, because food web effects of trawling are difficult to assess in a field or experimental setting. This model incorporates both lethal effects and non-lethal effects. Lethal effects are modelled as a mortality rate and non-lethal effects are modelled as a reduction in biomass production through a reduced intake rate. This approach was based on experiments with electric pulse and benthic invertebrates (PhD project J. Tiano, van Marlen et al. (2009)). The model was used to assess how strong non-lethal effects need to be to obtain the same food web effect as lethal effects. This provides a theoretical boundary of how strong non-lethal effects must be. All estimates of non-lethal effects that indicate that such levels are not reached in reality support the notion that the impact of the pulse trawl on the food web is less than that of the traditional trawl.

The results demonstrate that a reduction in lethal effects can be compensated by non-lethal effects to maintain total food web biomass and that non-lethal effects need to be the same order of magnitude as the lethal effects. Impact estimates of non-lethal effects of the pulse trawl on individuals already indicate that the such high levels of indirect effects are unlikely to occur in the field (PhD project J. Tiano, van Marlen et al. (2009)). The impact of the pulse trawl on the macro-invertebrate food web, taking non-lethal effects into account, will be less than that of the traditional beam trawl.

The strength of the non-lethal effects needed to compensate the loss of lethal effects depended on the trawling intensity. A higher trawling intensity resulted in a stronger required decrease of the intake rate. Thus, biomass removal from the system through lethal effects is replaced by a loss of biomass production through non-lethal effects. While the total biomass was kept constant, the biomass distribution among benthic groups changed with changing strength of lethal and non-lethal effects. If we were to assume that the pulse trawl imposes half of the lethal effects of the traditional beam trawl (Rijnsdorp, de Haan, Smith, \& Strietman, 2016), Figure 4 and Figure 5 imply that for high trawling intensities a simultaneous reduction to 0.8 of the intake rate is needed to maintain constant equilibrium community biomass. At low trawling intensities a smaller nonlethal effect suffices to maintain the equilibrium biomass of the benthic community. Any gear with non-lethal effects smaller than those required to compensate for its reduced lethal effects, is predicted to have a smaller overall impact on the benthic ecosystem than the traditional beam trawl using tickler chains. Experiments show that after exposure to an electric field comparable to that of a single passing of a pulse trawl, benthic invertebrate individuals remain inactive for no more than 20 minutes (J. Tiano unpublished). This implies a reduction in feeding time of 3\%, given a 12 hour feeding activity per day, on the day of passing. Converted to the intake rate as used in the model this means a downscaling of the rate to 0.97 of its value on the day of passing. The food web consequences are further affected by the frequency of exposure ( $\mathrm{Fe}$ ) during the daily and seasonal activity period of the animals. Assuming an activity period of $\mathrm{D}$ hours per day and an activity period of $\mathrm{N}$ days/year, a fasting response of $\mathrm{R}$ hours to an electrical disturbance event during the activity period of the animal would represent a Fe.R/D.N reduction in the food intake. Given a maximum exposure frequency to beam trawls of about 5 times per year (Eigaard et al., 2016), a daily activity period D of 12 hours, a seasonal activity period of 9 months (Braeckman et al., 2010), and a fasting response time of 0.3 hours, the likely non-lethal effect will be about a 0.0004 decrease in intake rate in a year at individual level.

Although the results from this model study are hard to relate to quantitative measurements, it appears that the decrease in individual intake rate suggested by the information available (Tiano et al, in prep) and as calculated above, is far less than what would be required for the non-lethal effect to make up for an assumed $50 \%$ reduction in lethal effects. The model presented here illustrates that non-lethal food web level effects implemented as a reduction in intake rate need to be quite severe for any effect to take place.

The model used in this study allows for non-linear feedback loops to occur. This gives rise to food web responses to trawling such as simultaneous negative and positive processes affecting biomass, which 
may be overlooked when considering only net effects of trawling. An increase in filter feeder biomass with trawling intensity is such a counter-intuitive result. Such an increase occurs when predator biomass is reduced by fishing mortality, releasing the filter feeders from predation pressure. The net result may then be an increase in total food web biomass but this may be accompanied by a decrease in diversity. The lack of consensus of bottom trawling effects on benthic macro-invertebrates and the wide error bars provided in meta-analyses may be partly explained by food web interactions (Collie, Hall, Kaiser, \& Poiner, 2000; Kaiser et al., 2006; Sciberras et al., 2018). The variation in response and consequent lack of significant effects in these studies is often attributed to inconsistencies in sampling design, data paucity or high background variation leading to low statistical power.

In conclusion, this study shows that lethal effects need to be replaced by non-lethal effects (reduced feeding activity) with similar strength in order to maintain the effect of trawling intensity on the food web. Such strong non-lethal effects are unlikely to occur in the field based on experiments assessing the impact of electricity on individual benthic macro-invertebrates (van Marlen et al., 2009) (Tiano et al. unpublished) and trawling intensity (Eigaard et al., 2016). 


\section{Quality Assurance}

Wageningen Marine Research utilises an ISO 9001:2015 certified quality management system. This certificate is valid until 15 December 2021. The organisation has been certified since 27 February 2001. The certification was issued by DNV GL. 


\section{References}

Bolam, S. G., Coggan, R. C., Eggieton, J., Diesing, M., \& Stephens, D. (2014). Sensitivity of macrobenthic secondary production to trawling in the English sector of the Greater North Sea: A biological trait approach. Journal of Sea Research, 85, 162-177. doi:10.1016/j.seares.2013.05.003

Braeckman, U., Provoost, P., Gribsholt, B., Van Gansbeke, D., Middelburg, J. J., Soetaert, K., . . . Vanaverbeke, J. (2010). Role of macrofauna functional traits and density in biogeochemical fluxes and bioturbation. Marine Ecology Progress Series, 399, 173-186.

Bremner, J., Rogers, S. I., \& Frid, C. L. J. (2006). Methods for describing ecological functioning of marinebenthic assemblages using biological traits analysis (BTA). Ecological Indicators, 6(3), 609622. doi:https://doi.org/10.1016/j.ecolind.2005.08.026

Collie, J. S., Hall, S. J., Kaiser, M. J., \& Poiner, I. R. (2000). A quantitative analysis of fishing impacts on shelf-sea benthos. Journal of Animal Ecology, 69(5), 785-798. doi:10.1046/j.13652656.2000.00434.x

Daan, R., \& Mulder, M. (2009). Monitoring the invertebrate benthic fauna in the Dutch sector of the North Sea 1991 - 2005: an overview NIOZ-Report

de Haan, D., Fosseidengen, J. E., Fjelldal, P. G., Burggraaf, D., \& Rijnsdorp, A. D. (2016). Pulse trawl fishing: characteristics of the electrical stimulation and the effect on behaviour and injuries of Atlantic cod (Gadus morhua). ICES Journal of Marine Science, 73(6), 1557-1569. doi:10.1093/icesjms/fsw018

De Roos, A. M., Schellekens, T., van Kooten, T., van de Wolfshaar, K. E., Claessen, D., \& Persson, L. (2007). Food-dependent growth leads to overcompensation in stage-specific Biomass when mortality increases: The influence of maturation versus reproduction regulation. The American Naturalist, 170(3), E59-E76. doi:10.1086/520119

De Roos, A. M., Schellekens, T., Van Kooten, T., van de Wolfshaar, K. E., Claessen, D., \& Persson, L. (2008). Simplifying a physiologically structured population model to a stage-structured biomass model. Theoretical Population Biology, 73(1), 47-62. doi:10.1016/j.tpb.2007.09.004

Depestele, J., Degrendele, K., Esmaeili, M., Ivanović, A., Kröger, S., O’Neill, F. G., . . Rijnsdorp, A. D. (2019). Comparison of mechanical disturbance in soft sediments due to tickler-chain SumWing trawl vs. electro-fitted PulseWing trawl. ICES Journal of Marine Science, 76(1), 312-329. doi:10.1093/icesjms/fsy124

Eigaard, O. R., Bastardie, F., Hintzen, N. T., Buhl-Mortensen, L., Buhl-Mortensen, P., Catarino, R., . . . Rijnsdorp, A. D. (2016). The footprint of bottom trawling in European waters: distribution, intensity, and seabed integrity. ICES Journal of Marine Science, 74(3), 847-865. doi:10.1093/icesjms/fsw194

Gillooly, J. F., Brown, J. H., West, G. B., Savage, V. M., \& Charnov, E. L. (2001). Effects of size and temperature on metabolic rate. Science, 293, 2248-2251.

Haasnoot, T., Kraan, M., \& Bush, S. R. (2016). Fishing gear transitions: lessons from the Dutch flatfish pulse trawl. ICES Journal of Marine Science, 73(4), 1235-1243. doi:10.1093/icesjms/fsw002

Hiddink, J. G., Jennings, S., Sciberras, M., Bolam, S. G., Cambie, G., McConnaughey, R. A., . . . Rijnsdorp, A. D. (2019). Assessing bottom trawling impacts based on the longevity of benthic invertebrates. Journal of Applied Ecology, 56(5), 1075-1084. doi:10.1111/1365-2664.13278

ICES. (2018). Report of the Working Group on Electric Trawling (WGELECTRA). ICES Report WGELECTRA 201817 - 19 April 2018. IJmuiden, the Netherlands. 155pp. Retrieved from

Kaiser, M. J., Clarke, K. D., Hinz, H., Austen, M. C. V., Somerfield, P. J., \& Karakassis, I. (2006). Global analysis of response and recovery of benthic biota to fishing. Marine Ecology Progress Series, 311, 1-14. doi: $10.3354 /$ meps 311001

Kuznetsov, Y. A., Levitin, V. V., \& Skovoroda, A. R. (1996). Continuation of stationary solutions to evolution problems in Content. Centre for Mathematics and Computer Science

O'Neill, F. G., \& Summerbell, K. (2011). The mobilisation of sediment by demersal otter trawls. Marine Pollution Bulletin, 62(5), 1088-1097. doi:10.1016/j.marpolbul.2011.01.038

Peters, R. H., \& Wassenberg, K. (1983). The effect of body size on animal abundance. Oecologia, 60(1), 8996. doi: $10.1007 /$ bf00379325

Rijnsdorp, A. D., de Haan, D., Smith, S., \& Strietman, W. J. (2016). Pulse fishing and its effects on the marine ecosystem and fisheries. An update of the scientific knowledge. Wageningen Marine Research report $\mathrm{C} 117 / 16$ 
Sciberras, M., Hiddink, J. G., Jennings, S., Szostek, C. L., Hughes, K. M., Kneafsey, B., . . Kaiser, M. J. (2018). Response of benthic fauna to experimental bottom fishing: A global meta-analysis. Fish and Fisheries, 19(4), 698-715. doi:10.1111/faf.12283

Smaal, A. C., \& Brummelhuis, E. (2005). Onderzoek naar mogelijke effecten van de pulskor op bodemdieren. Retrieved from

Soetaert, M., Chiers, K., Duchateau, L., Polet, H., Verschueren, B., \& Decostere, A. (2015). Determining the safety range of electrical pulses for two benthic invertebrates: brown shrimp (Crangon crangon L.) and ragworm (Alitta virens S.). ICES Journal of Marine Science, 72(3), 973-980. doi: $10.1093 /$ icesjms/fsu176

Soetaert, M., Decostere, A., Polet, H., Verschueren, B., \& Chiers, K. (2015). Electrotrawling: a promising alternative fishing technique warranting further exploration. Fish and Fisheries, 16, 104-124.

Soetaert, M., Verschueren, B., Chiers, K., Duchateau, L., Polet, H., \& Decostere, A. (2016). Laboratory Study of the Impact of Repetitive Electrical and Mechanical Stimulation on Brown Shrimp Crangon crangon. Marine and Coastal Fisheries, 8(1), 404-411. doi:10.1080/19425120.2016.1180333

Tilman, D., \& Sterner, R. W. (1984). Invastions of equilibria - tests of resource competition using 2 species of algae. Oecologia, 61(2), 197-200. doi:10.1007/bf00396760

van Denderen, P. D., Bolam, S. G., Hiddink, J. G., Jennings, S., Kenny, A., Rijnsdorp, A. D., \& van Kooten, T. (2015). Similar effects of bottom trawling and natural disturbance on composition and function of benthic communities across habitats. Marine Ecology Progress Series, 541, 31-43.

van Denderen, P. D., Hintzen, N. T., Rijnsdorp, A. D., Ruardij, P., \& van Kooten, T. (2014). Habitat-Specific Effects of Fishing Disturbance on Benthic Species Richness in Marine Soft Sediments. Ecosystems, 17(7), 1216-1226. doi:10.1007/s10021-014-9789-x

Van Leeuwen, A., De Roos, A. M., \& Persson, L. (2008). How cod shapes its world. [Dynamics of Fish and Fishers, A symposium on Sustainable Management of Marine Living Resources. Food for Thought: Dynamics of Fish and Fishers]. Journal of Sea Research, 60(1-2), 89-104.

van Marlen, B., de Haan, D., van Gool, A. C. M., \& Burggraaf, D. (2009). The effect of pulse stimulation on marine biota - Research in relation to ICES advice - Progress report on the effects on benthic invertebrates. Retrieved from IJmuiden: http://edepot.wur.nl/133166

van Marlen, B., Wiegerinck, J. A. M., van Os-Koomen, E., \& van Barneveld, E. (2014). Catch comparison of flatfish pulse trawls and a tickler chain beam trawl. Fisheries Research, 151, 57-69. doi: 10.1016/j.fishres.2013.11.007

Bolam, S. G., Coggan, R. C., Eggieton, J., Diesing, M., \& Stephens, D. (2014). Sensitivity of macrobenthic secondary production to trawling in the English sector of the Greater North Sea: A biological trait approach. Journal of Sea Research, 85, 162-177. doi:10.1016/j.seares.2013.05.003

Braeckman, U., Provoost, P., Gribsholt, B., Van Gansbeke, D., Middelburg, J. J., Soetaert, K., . . . Vanaverbeke, J. (2010). Role of macrofauna functional traits and density in biogeochemical fluxes and bioturbation. Marine Ecology Progress Series, 399, 173-186.

Bremner, J., Rogers, S. I., \& Frid, C. L. J. (2006). Methods for describing ecological functioning of marinebenthic assemblages using biological traits analysis (BTA). Ecological Indicators, 6(3), 609622. doi:https://doi.org/10.1016/j.ecolind.2005.08.026

Collie, J. S., Hall, S. J., Kaiser, M. J., \& Poiner, I. R. (2000). A quantitative analysis of fishing impacts on shelf-sea benthos. Journal of Animal Ecology, 69(5), 785-798. doi:10.1046/j.13652656.2000.00434.x

Daan, R., \& Mulder, M. (2009). Monitoring the invertebrate benthic fauna in the Dutch sector of the North Sea 1991 - 2005: an overview Retrieved from

de Haan, D., Fosseidengen, J. E., Fjelldal, P. G., Burggraaf, D., \& Rijnsdorp, A. D. (2016). Pulse trawl fishing: characteristics of the electrical stimulation and the effect on behaviour and injuries of Atlantic cod (Gadus morhua). ICES Journal of Marine Science, 73(6), 1557-1569. doi: $10.1093 /$ icesjms/fsw018

De Roos, A. M., Schellekens, T., van Kooten, T., van de Wolfshaar, K. E., Claessen, D., \& Persson, L. (2007). Food-dependent growth leads to overcompensation in stage-specific Biomass when mortality increases: The influence of maturation versus reproduction regulation. The American Naturalist, 170(3), E59-E76. doi:10.1086/520119

De Roos, A. M., Schellekens, T., Van Kooten, T., van de Wolfshaar, K. E., Claessen, D., \& Persson, L. (2008). Simplifying a physiologically structured population model to a stage-structured biomass model. Theoretical Population Biology, 73(1), 47-62. doi:10.1016/j.tpb.2007.09.004

Depestele, J., Degrendele, K., Esmaeili, M., Ivanović, A., Kröger, S., O’Neill, F. G., . . Rijnsdorp, A. D. (2019). Comparison of mechanical disturbance in soft sediments due to tickler-chain SumWing trawl vs. electro-fitted PulseWing trawl. ICES Journal of Marine Science, 76(1), 312-329. doi:10.1093/icesjms/fsy124 
Eigaard, O. R., Bastardie, F., Hintzen, N. T., Buhl-Mortensen, L., Buhl-Mortensen, P., Catarino, R., . . . Rijnsdorp, A. D. (2016). The footprint of bottom trawling in European waters: distribution, intensity, and seabed integrity. ICES Journal of Marine Science, 74(3), 847-865. doi:10.1093/icesjms/fsw194

Gillooly, J. F., Brown, J. H., West, G. B., Savage, V. M., \& Charnov, E. L. (2001). Effects of size and temperature on metabolic rate. Science, 293, 2248-2251.

Haasnoot, T., Kraan, M., \& Bush, S. R. (2016). Fishing gear transitions: lessons from the Dutch flatfish pulse trawl. ICES Journal of Marine Science, 73(4), 1235-1243. doi:10.1093/icesjms/fsw002

Hiddink, J. G., Jennings, S., Sciberras, M., Bolam, S. G., Cambie, G., McConnaughey, R. A., . . Rijnsdorp, A. D. (2019). Assessing bottom trawling impacts based on the longevity of benthic invertebrates. Journal of Applied Ecology, 56(5), 1075-1084. doi:10.1111/1365-2664.13278

ICES. (2018). Report of the Working Group on Electric Trawling (WGELECTRA). ICES Report WGELECTRA 201817 - 19 April 2018. IJmuiden, the Netherlands. 155pp. Retrieved from

Kaiser, M. J., Clarke, K. D., Hinz, H., Austen, M. C. V., Somerfield, P. J., \& Karakassis, I. (2006). Global analysis of response and recovery of benthic biota to fishing. Marine Ecology Progress Series, 311, 1-14. doi: $10.3354 /$ meps 311001

Kuznetsov, Y. A., Levitin, V. V., \& Skovoroda, A. R. (1996). Continuation of stationary solutions to evolution problems in Content. Retrieved from Amsterdam:

O'Neill, F. G., \& Summerbell, K. (2011). The mobilisation of sediment by demersal otter trawls. Marine Pollution Bulletin, 62(5), 1088-1097. doi:10.1016/j.marpolbul.2011.01.038

Peters, R. H., \& Wassenberg, K. (1983). The effect of body size on animal abundance. Oecologia, 60(1), 8996. doi: $10.1007 /$ bf00379325

Rijnsdorp, A. D., de Haan, D., Smith, S., \& Strietman, W. J. (2016). Pulse fishing and its effects on the marine ecosystem and fisheries. An update of the scientific knowledge. Retrieved from

Sciberras, M., Hiddink, J. G., Jennings, S., Szostek, C. L., Hughes, K. M., Kneafsey, B., . . Kaiser, M. J. (2018). Response of benthic fauna to experimental bottom fishing: A global meta-analysis. Fish and Fisheries, 19(4), 698-715. doi:10.1111/faf.12283

Smaal, A. C., \& Brummelhuis, E. (2005). Onderzoek naar mogelijke effecten van de pulskor op bodemdieren. Retrieved from

Soetaert, M., Chiers, K., Duchateau, L., Polet, H., Verschueren, B., \& Decostere, A. (2015). Determining the safety range of electrical pulses for two benthic invertebrates: brown shrimp (Crangon crangon L.) and ragworm (Alitta virens S.). ICES Journal of Marine Science, 72(3), 973-980. doi:10.1093/icesjms/fsu176

Soetaert, M., Decostere, A., Polet, H., Verschueren, B., \& Chiers, K. (2015). Electrotrawling: a promising alternative fishing technique warranting further exploration. Fish and Fisheries, 16, 104-124.

Soetaert, M., Verschueren, B., Chiers, K., Duchateau, L., Polet, H., \& Decostere, A. (2016). Laboratory Study of the Impact of Repetitive Electrical and Mechanical Stimulation on Brown Shrimp Crangon crangon. Marine and Coastal Fisheries, 8(1), 404-411. doi:10.1080/19425120.2016.1180333

Tilman, D., \& Sterner, R. W. (1984). Invastions of equilibria - tests of resource competition using 2 species of algae. Oecologia, 61(2), 197-200. doi:10.1007/bf00396760

van Denderen, P. D., Bolam, S. G., Hiddink, J. G., Jennings, S., Kenny, A., Rijnsdorp, A. D., \& van Kooten, T. (2015). Similar effects of bottom trawling and natural disturbance on composition and function of benthic communities across habitats. Marine Ecology Progress Series, 541, 31-43.

van Denderen, P. D., Hintzen, N. T., Rijnsdorp, A. D., Ruardij, P., \& van Kooten, T. (2014). Habitat-Specific Effects of Fishing Disturbance on Benthic Species Richness in Marine Soft Sediments. Ecosystems, 17(7), 1216-1226. doi:10.1007/s10021-014-9789-x

Van de Wolfshaar, K.E., van Denderen, P.D., Schellekens, T., \& van Kooten, T. under review. Food web feedbacks drive the response of benthic macrofauna to bottom trawling.

Van Leeuwen, A., De Roos, A. M., \& Persson, L. (2008). How cod shapes its world. [Dynamics of Fish and Fishers, A symposium on Sustainable Management of Marine Living Resources. Food for Thought: Dynamics of Fish and Fishers]. Journal of Sea Research, 60(1-2), 89-104.

van Marlen, B., de Haan, D., van Gool, A. C. M., \& Burggraaf, D. (2009). The effect of pulse stimulation on marine biota - Research in relation to ICES advice - Progress report on the effects on benthic invertebrates. Retrieved from IJmuiden: http://edepot.wur.nl/133166

van Marlen, B., Wiegerinck, J. A. M., van Os-Koomen, E., \& van Barneveld, E. (2014). Catch comparison of flatfish pulse trawls and a tickler chain beam trawl. Fisheries Research, 151, 57-69. doi: $10.1016 /$ j.fishres.2013.11.007 


\section{Justification}

\section{Report C011.20}

Project Number: 43.141.000.10

The scientific quality of this report has been peer reviewed by the a colleague scientist and the head of the department of Wageningen Marine Research.

$\begin{array}{ll}\text { Approved: } & \text { Ir. Edward Schram } \\ & \text { Researcher }\end{array}$

Signature:

Date:

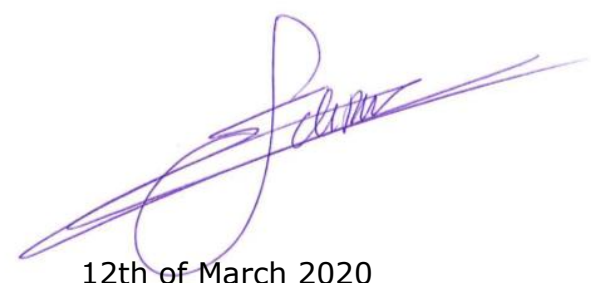

12th of March 2020

Approved: $\quad$ Dr. ir. T.P. Bult

Director

Signature:

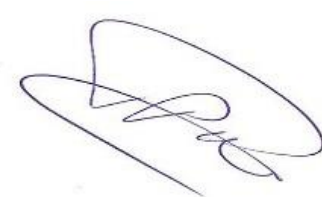

Date:

12th of March 2020 
Wageningen Marine Research

T +31 (0)317480900

E: marine-research@wur.nl

www.wur.eu/marine-research

Visitors' address

- Ankerpark 271781 AG Den Helder

- Korringaweg 7, 4401 NT Yerseke

- Haringkade 1, 1976 CP IJmuiden
With knowledge, independent scientific research and advice, Wageningen Marine Research substantially contributes to more sustainable and more careful management, use and protection of natural riches in marine, coastal and freshwater areas.
Wageningen Marine Research is part of Wageningen University \& Research. Wageningen University \& Research is the collaboration between Wageningen University and the Wageningen Research Foundation and its mission is: 'To explore the potential for improving the quality of life' 